\title{
Calix[6]arene-based atropoisomeric pseudo[2]rotaxanes
}

\author{
Carmine Gaeta, Carmen Talotta ${ }^{*}$ and Placido Neri
}

\author{
Full Research Paper \\ Address: \\ Dipartimento di Chimica e Biologia " A. Zambelli", Università di \\ Salerno, Via Giovanni Paolo II 132, 84084 Fisciano (Salerno), Italy \\ Email: \\ Carmen Talotta* - ctalotta@unisa.it \\ * Corresponding author \\ Keywords: \\ atropoisomers; calixarene; conformation; pseudorotaxane; social \\ isomerism
}

Open Access

Beilstein J. Org. Chem. 2018, 14, 2112-2124.
doi:10.3762/bjoc.14.186
Received: 02 May 2018
Accepted: 26 July 2018
Published: 14 August 2018
This article is part of the thematic issue "Macrocyclic and supramolecular
chemistry".
Guest Editor: M.-X. Wang
C 2018 Gaeta et al.; licensee Beilstein-Institut.
License and terms: see end of document.

\begin{abstract}
Some examples of atropoisomeric pseudorotaxanes in which the isomerism arises by the different conformations adopted by the wheel are reported here. Upon threading hexahexyloxycalix[6] arene $\mathbf{1}$ with ammonium axles $\mathbf{2}^{+}$or $\mathbf{3}^{+}$, bearing biphenyl or trifluoromethylbenzyl moieties, respectively, two atropoisomeric pseudorotaxanes were formed in which the calix[6]-wheel 1 adopts the 1,2,3-alternate and cone conformations. The interconversion between them cannot be obtained by simple rotation around the $\mathrm{ArCH}_{2} \mathrm{Ar}$ bonds of the calixarene wheel, which is blocked by the presence of the axle inside its cavity. Therefore, it can only be obtained through a mechanism of de-threading/re-threading of the axle. In all the examined cases, the 1,2,3-alternate and cone atropoisomers are, respectively, the kinetic and the thermodynamic ones.
\end{abstract}

\section{Introduction}

Mechanomolecules [1-4], such as rotaxanes and catenanes show interesting properties as nanodevices for catalysis [5-8], recognition, and sensing [9-13]. Beyond these ascertained potentialities, interpenetrated architectures show fascinating structures that still stimulate the imagination of scientists.

An amazing aspect of rotaxanes and catenanes is their ability to adopt novel forms of isomerism. More in detail, (pseudo)rotaxane or catenane architectures can show novel stereoisomeric forms as a result of the "social" [14] relationship between their components.
Recently, Goldup's group assembled a mechanically planar chiral rotaxane [15,16] (I and $\mathbf{I}^{*}$, Figure 1) consisting of achiral components. The combination of a macrocycle with rotational asymmetry and a directional thread with non-equivalent ends is the cause of chirality in this example (Figure 1). Interestingly, our group showed that a chiral pseudorotaxane can be generated upon threading a tertiary ammonium axles in a directional (non-flat) calixarene-wheel (II and II*, Figure 1) [17]. In this case the chirality is created by the directionality of the calixarene wheel in a cone conformation, which differentiates the two alkyl chains around the prochiral ammonium center. 


\section{at.}

I

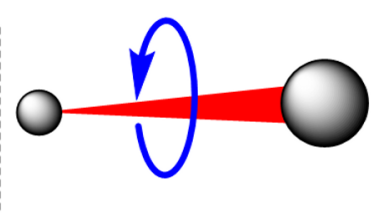

$I^{*}$

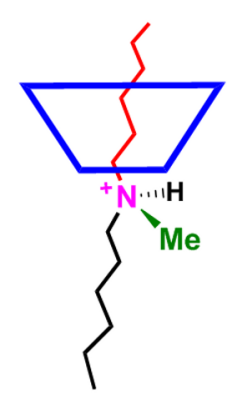

II

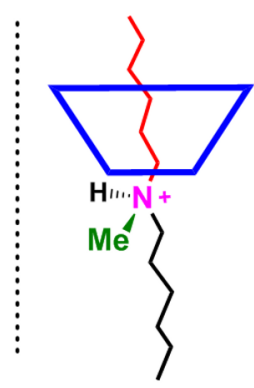

II
Figure 1: Cartoon representation of the chiral rotaxane of the Goldup group $[15,16]\left(\mathbf{I}\right.$ and $\left.\mathbf{I}^{\star}\right)$ and of the chiral pseudorotaxane (II and II*) reported by our group [17].

In 2010, for the first time, an example of sequence isomerism was reported by Leigh's group [18], caused by two different flat wheels that can be located differently along a directional thread III and IV (Figure 2). As an evolution of this concept, we envisaged a sequence stereoisomerism if two directional nonflat wheels, such as calixarenes or cyclodextrins, are threaded along an axle to give a pseudo[3]rotaxane architecture V-VII (Figure 2), where three sequential stereoisomers can arise. We showed that this stereoisomerism can be effectively controlled when two calix[6]arene wheels are threaded along a bis(benzylalkylammonium) axle [19], where the stereoselective formation of the pseudo[3]rotaxane with endo-alkyl orientation VIII was observed [19].

Calixarene macrocycles [22] have found numerous applications in several areas of supramolecular chemistry, such as (bio)molecular recognition [23] and catalysis [24]. The widespread use of the calixarene derivatives is due to their convenient synthesis and to their chemical and conformational versatility [25]. In fact, calixarene macrocycles present a conformational isomerism that in the case of calix[6]arenes gives rise to eight discrete conformations (Figure 3) [26]: cone, partial-cone, 1,2alternate, 1,3-alternate, 1,4-alternate, 1,2,3-alternate, 1,2,4alternate, and 1,3,5-alternate. This conformational versatility has long attracted much attention, and therefore empirical rules have been reported in order to assign the calixarene conformations [27,28]. The "H NMR $\Delta \delta$ " rule reported by Gutsche [29], is focused on the difference of chemical shifts between each

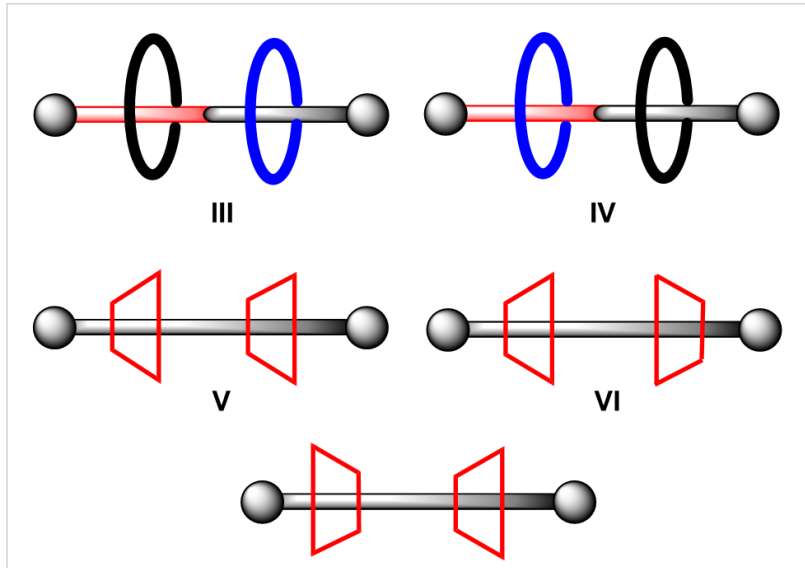

VII

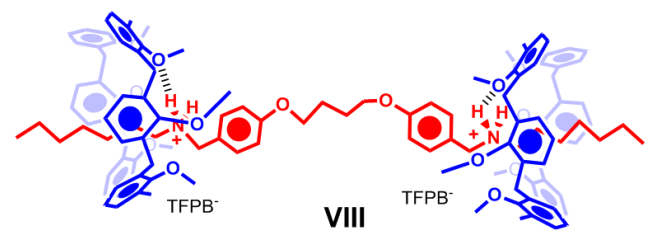

Figure 2: Cartoon representation of the rotaxane sequence isomers reported by Leigh [17] (III and IV) and of the pseudorotaxane sequential stereoisomers (V-VII) reported by our group [19-21].

pair of calixarene $\mathrm{ArCH}_{2} \mathrm{Ar}$ methylene protons. These can show diasterotopicity resulting in AX or AB systems. Specifically, a ${ }^{1} \mathrm{H}$ NMR methylene proton $\Delta \delta$ value of at least 0.7 shows that the two respective proximal aromatic rings are oriented $s y n$, as in the cone conformation. In contrast, a $\Delta \delta$ value of 0.3 or less is attributable to an anti-orientation between the phenol rings, as in alternate conformations. The de Mendoza's " ${ }^{13} \mathrm{C}$ NMR single rule" [30,31], is focused on the ${ }^{13} \mathrm{C}$ NMR chemical shift of the $\mathrm{ArCH}_{2} \mathrm{Ar}$ methylene $\mathrm{C}$, which is $30-33$ ppm for the syn-orientation of the proximal phenol rings and typically $36-39 \mathrm{ppm}$ with anti-positioned phenol rings as in alternate conformations.

As exemplified above, the calix[6]arene macrocycle has been widely used as wheel for the assembly of pseudorotaxane architectures $[32,33]$, where it usually adopts a cone conformation. The examples reported by us [33-38] (Figure 4b) and by Arduini [32,39] (Figure 4a) showed that the directionality of the calixarene wheel in the cone conformation plays a pivotal role in the formation of stereoisomeric directional pseudo[2]rotaxanes, rotaxanes, and catenanes. Also in this case [38], we were able to obtain a stereoselective threading of the cone calix[6]arene-wheel with alkylbenzylammonium axles (Figure 4b), in which the endo-alkyl pseudo[2]rotaxane stereoisomer was the favoured one [38].

The threading of calix[6]arene macrocycles in conformations different than the cone one has been rarely observed [17]. Interestingly, the assembling of interpenetrated structures in which 

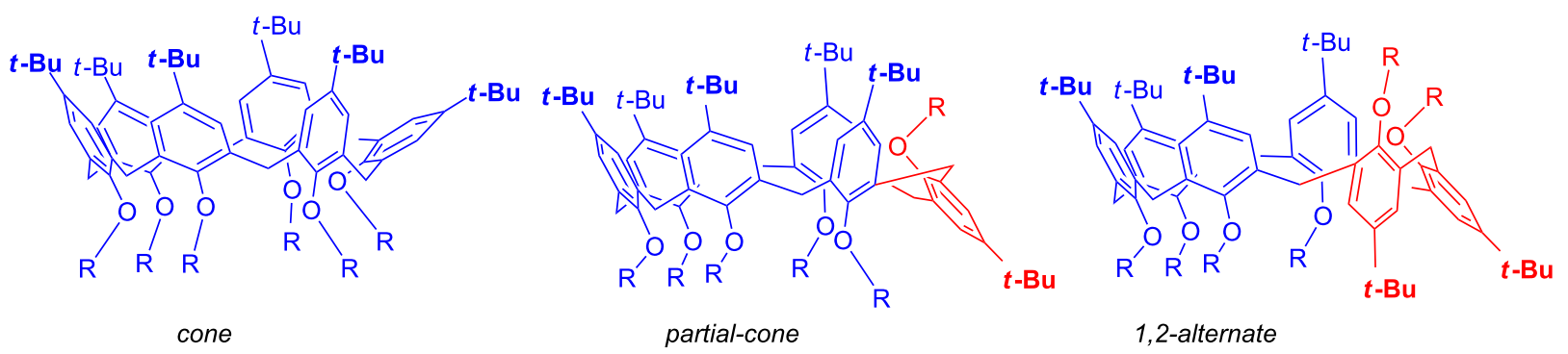

1,2-alternate

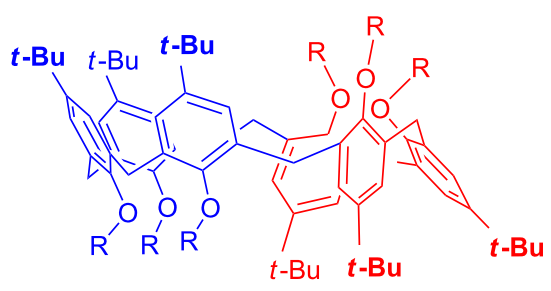

1,2,3-alternate

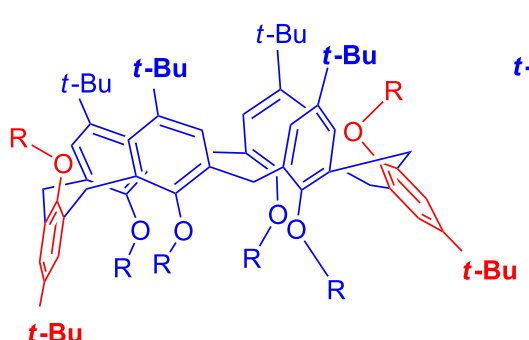

1,4-alternate

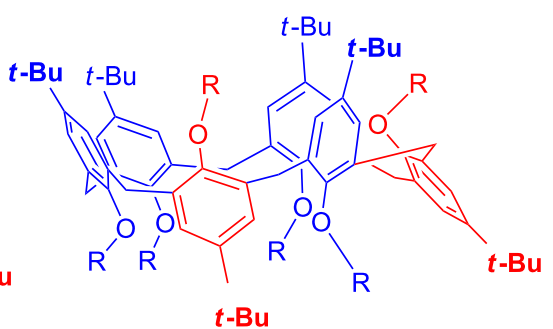

1,3-alternate
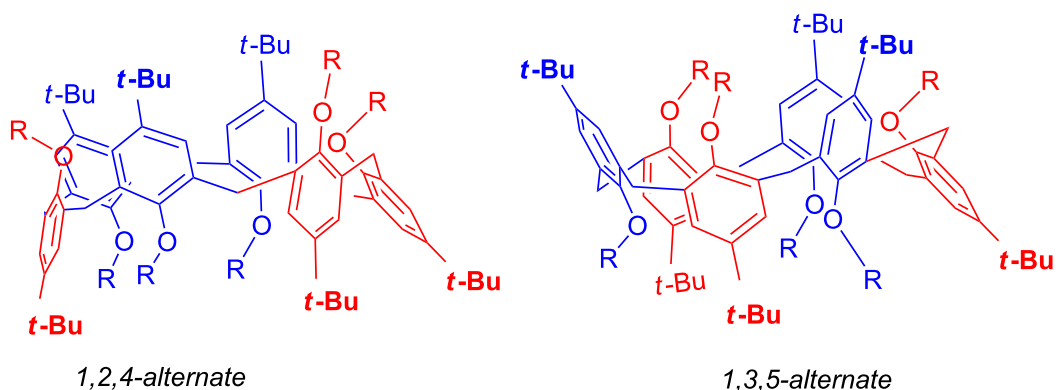

Figure 3: The possible 8 discrete conformations of a calix[6]arene macrocycle [26]

the wheel adopts different conformational isomers, could pave the way to mechanomolecules which exhibit novel isomeric forms.

Prompted by these considerations, some examples of pseudorotaxane isomers in which the isomerism arises by the different conformations adopted by the calixarene wheel are reported here.

\section{Results and Discussion}

With this goal in mind, we conducted an initial screening in order to select the ammonium axles and the calix[6]arene-wheel most suitable for our purposes. At the end of our screening, we focused our attention on hexahexyloxycalix[6]arene $\mathbf{1}$ as the wheel and bis(4-biphenylmethyl)ammonium $\left(2^{+}\right)$and bis(4-trifluoromethylbenzyl)ammonium $\left(\mathbf{3}^{+}, \mathrm{TFPB}^{-}\right.$salts $)$as the threads. The synthetic pathway to $2^{+} \cdot \mathrm{TFPB}^{-}$and $\mathbf{3}^{+} \cdot \mathrm{TFPB}^{-}$salts is outlined in Scheme 1, while calix[6]arene 1 was obtained following a known procedure [40].
The ${ }^{1} \mathrm{H}$ NMR spectrum of hexahexyloxycalix[6]arene $\mathbf{1}$ in $\mathrm{CDCl}_{3}$ at $298 \mathrm{~K}$ shows broad $\mathrm{ArCH}_{2} \mathrm{Ar}$ signals indicative of a conformational mobility of the macrocycle in which the inversion between the calix[6]arene conformations (Figure 5), occurs by means of rotation around the $\mathrm{ArCH}_{2} \mathrm{Ar}$ bonds.

By lowering the temperature, the $\mathrm{ArCH}_{2} \mathrm{Ar}$ signal decoalesced to form a single AX system (3.34/4.49 ppm) and one broad singlet $(3.77 \mathrm{ppm})$. This pattern is only compatible with the presence of a 1,2,3-alternate conformation of calix[6]arene 1 (Figure 5). This was confirmed by a 2D HSQC spectrum of $\mathbf{1}$ at $233 \mathrm{~K}$ which evidenced the presence of $\mathrm{ArCH}_{2} \mathrm{Ar}$ correlations between the AX system at 3.34/4.49 ppm with a carbon resonance at $29.4 \mathrm{ppm}$, related to syn-oriented Ar rings [29]. Diagnostic of the presence of the 1,2,3-alternate conformation of $\mathbf{1}$ is the presence of the broad singlet at $3.71 \mathrm{ppm}$ which correlates in the HSQC spectrum with a carbon resonance at $34.1 \mathrm{ppm}$ [30], related to anti-oriented Ar rings. A close inspection of the $1 \mathrm{D}$ and $2 \mathrm{D}$ NMR spectrum of $\mathbf{1}$ in $\mathrm{CDCl}_{3}$ at $233 \mathrm{~K}$ 

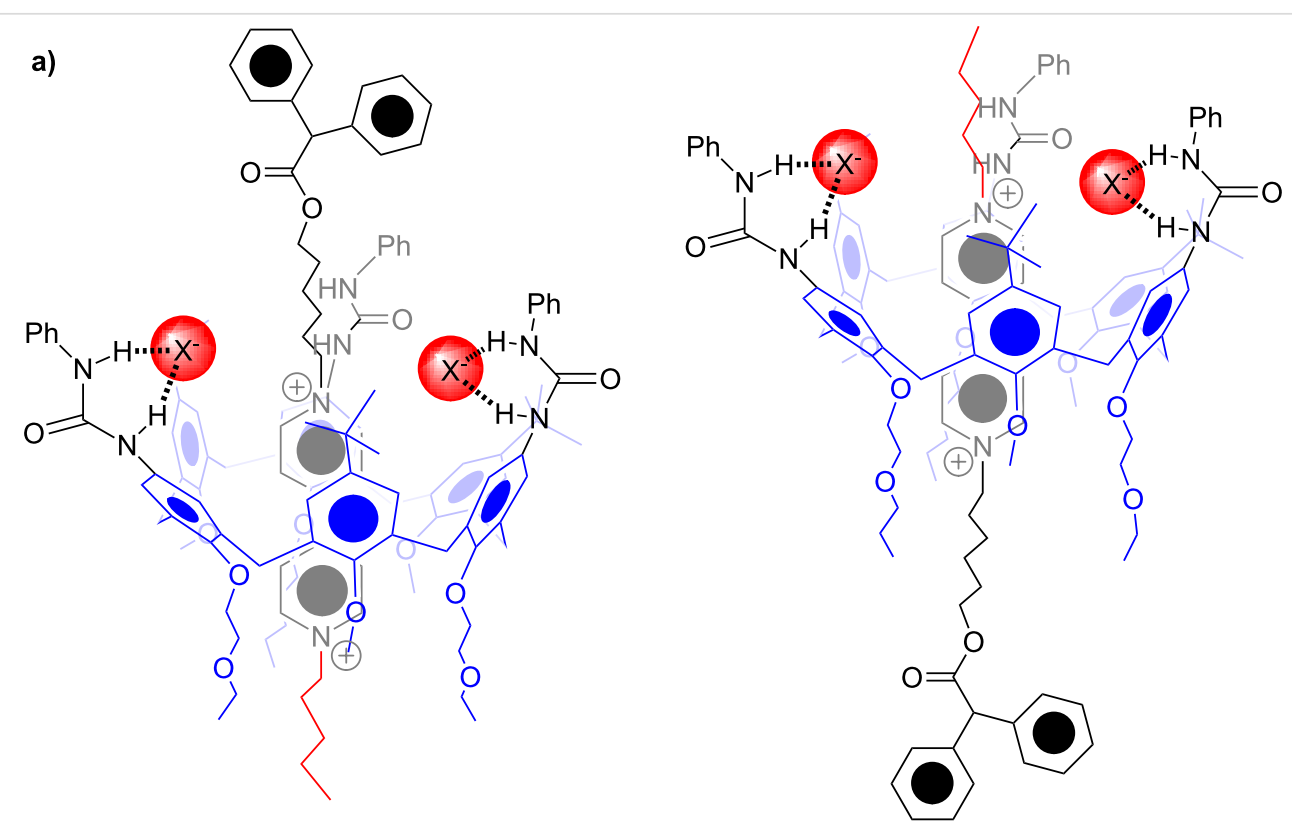

preferred in apolar solvent

b)

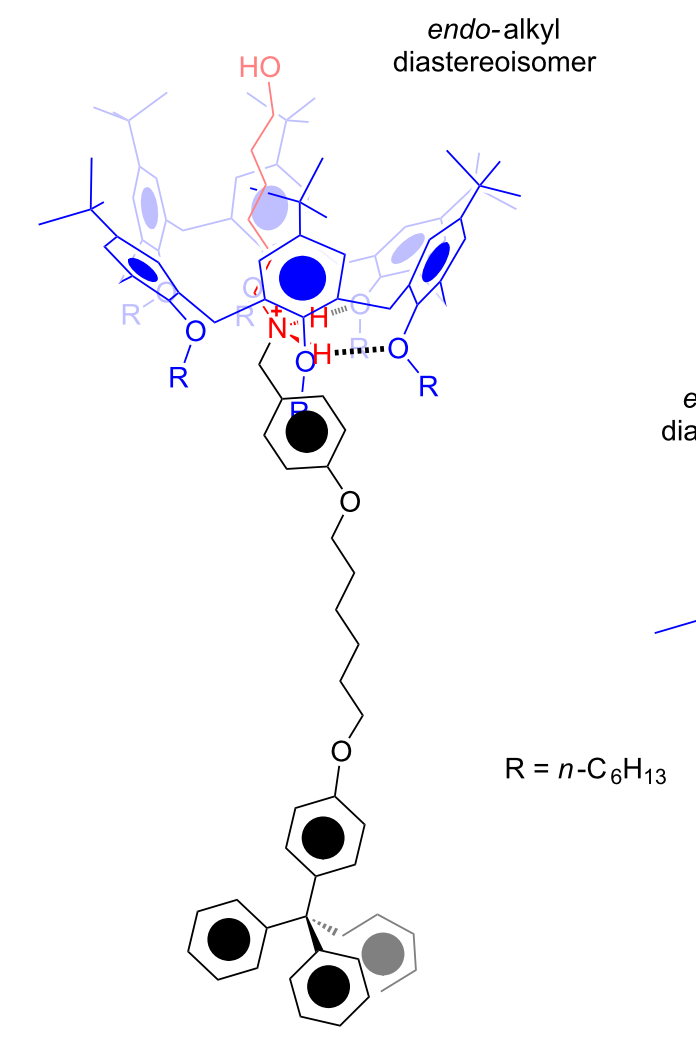

endo-alkyl

preferred

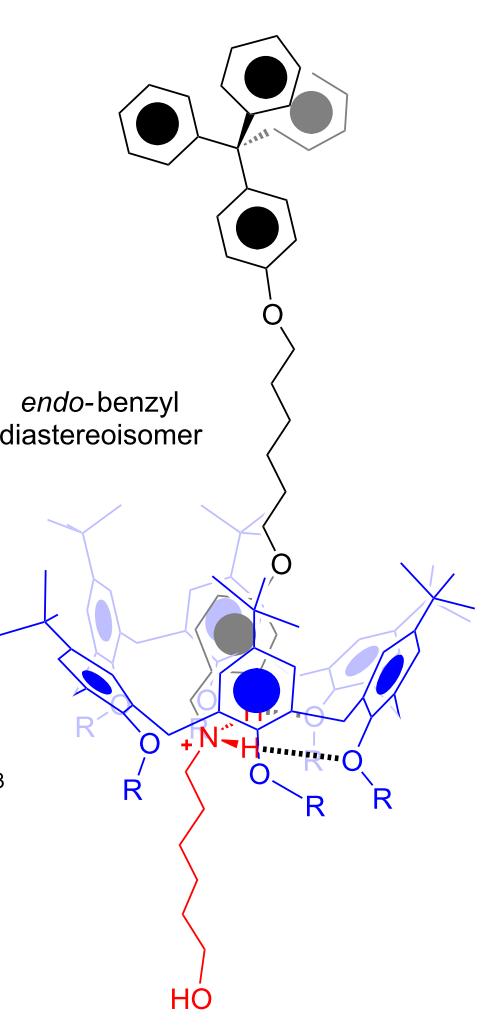

Figure 4: Diastereoisomeric pseudorotaxanes obtained by threading a directional calixarene wheel with directional axles.

clearly evidenced the presence of a less abundant conformer of 1. The nature of this minor conformer can be inferred by the work of Reinhoudt and co-workers which showed [41] that the conformations preferentially adopted by calix[6]arene hexa- ethers are the cone and 1,2,3-alternate ones. In accordance, 2D COSY and HSQC spectra of 1 at $233 \mathrm{~K}$ clarified that this minor conformer was the cone one through the presence of an AX system at 3.35/4.42 ppm (COSY), which correlates with a 


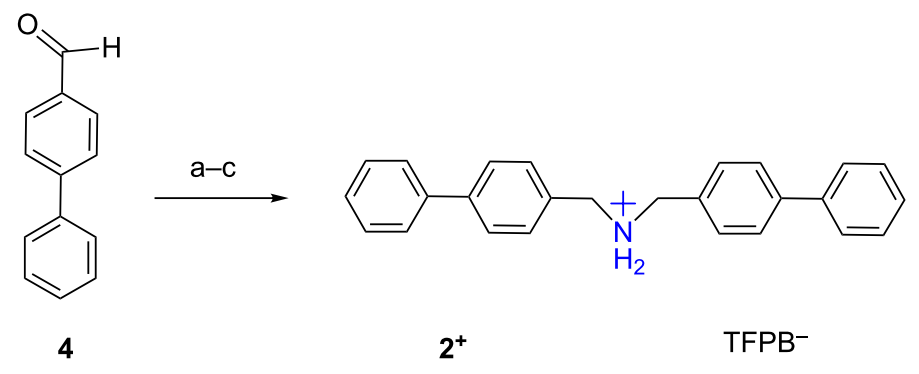

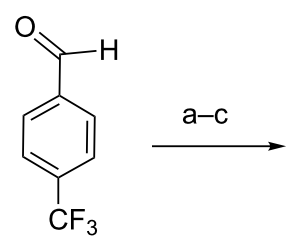

5<smiles>FC(F)(F)c1ccc(CNCc2ccc(C(F)(F)F)cc2)cc1</smiles>

$3^{+}$<smiles>FC(F)(F)c1cc([B-](c2cc(C(F)(F)F)cc(C(F)(F)F)c2)(c2cc(C(F)(F)F)cc(C(F)(F)F)c2)c2cc(C(F)(F)F)cc(C(F)(F)F)c2)cc(C(F)(F)F)c1</smiles>

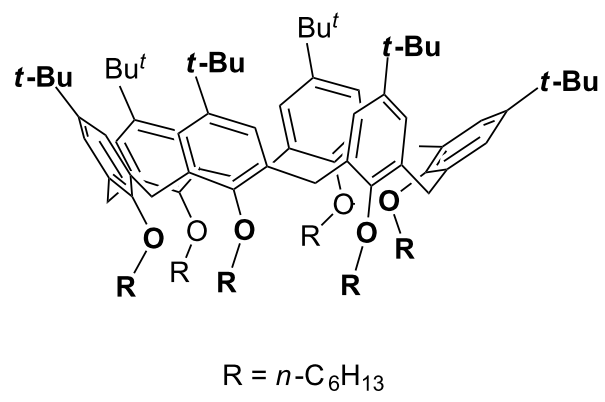

1

Scheme 1: Synthesis of threads $\mathbf{2}^{+}$and $\mathbf{3}^{+}$. Reagents and conditions: a) hexamethyldisilazane, $\mathrm{LiClO}_{4}, 30 \mathrm{~min}, 60{ }^{\circ} \mathrm{C}$; b) $\mathrm{CH}_{3} \mathrm{OH}, \mathrm{NaBH}_{4}, 2 \mathrm{~h}, 25^{\circ} \mathrm{C}$; c) TFPBNa, dry $\mathrm{MeOH}, 25^{\circ} \mathrm{C}, 18 \mathrm{~h}$.

carbon resonance at $29.1 \mathrm{ppm}$ (HSQC), related to syn-oriented Ar rings (cone conformation). The coalescence temperature of the methylene protons was ascertained at $328 \mathrm{~K}$ in $\mathrm{CDCl}_{3}$; below this temperature the conformations of 1 were frozen, while at temperatures above $328 \mathrm{~K}$ the conformational interconversion is fast with respect to the NMR time scale (400 MHz). From the coalescence data we calculated a barrier of $14.6 \mathrm{kcal} / \mathrm{mol}$ for this process. In summary, the VT ${ }^{1} \mathrm{H}$ NMR studies indicate that the 1,2,3-alternate is the most stable conformation for hexahexyloxycalix[6]arene $\mathbf{1}$ in solution. This conclusion is in perfect accord with the results previously reported by Reinhoudt [41], which evidenced an increased stabilization of the 1,2,3-alternate conformation of calix[6]arenes when the alkyl substituents at the lower rim are increased in size [41].
As expected [40], no evidence of interaction between $\mathbf{2}^{+}$and $\mathbf{1}$ was detected by NMR, when $\mathbf{2}^{+}$was added as its chloride salt to a $\mathrm{CDCl}_{3}$ solution of $\mathbf{1}$. However, when $\mathbf{2}^{+}$was added as its $\mathrm{TFPB}^{-}$salt to a $\mathrm{CDCl}_{3}$ solution of $\mathbf{1}$, then dramatic changes were observed in the ${ }^{1} \mathrm{H}$ NMR spectrum of $\mathbf{1}$ (Figure 6).

In detail, immediately after the mixing of $\mathbf{1}$ and $\mathbf{2}^{+}$we observed the sharpening of all signals and the appearance of an AX system at 5.50/6.70 ppm attributable to aromatic $\mathrm{H}$-atoms of the axle $2^{+}$shielded inside the calixarene cavity. These changes were indicative of the formation of a pseudorotaxane $2^{+} \subset \mathbf{1}$. With this result in hand, we turned our attention to the conformation adopted by the calix[6] arene-wheel $\mathbf{1}$ in pseudorotaxane $2^{+} \subset \mathbf{1}$. A 2 D COSY spectrum of $1: 1$ mixture of 


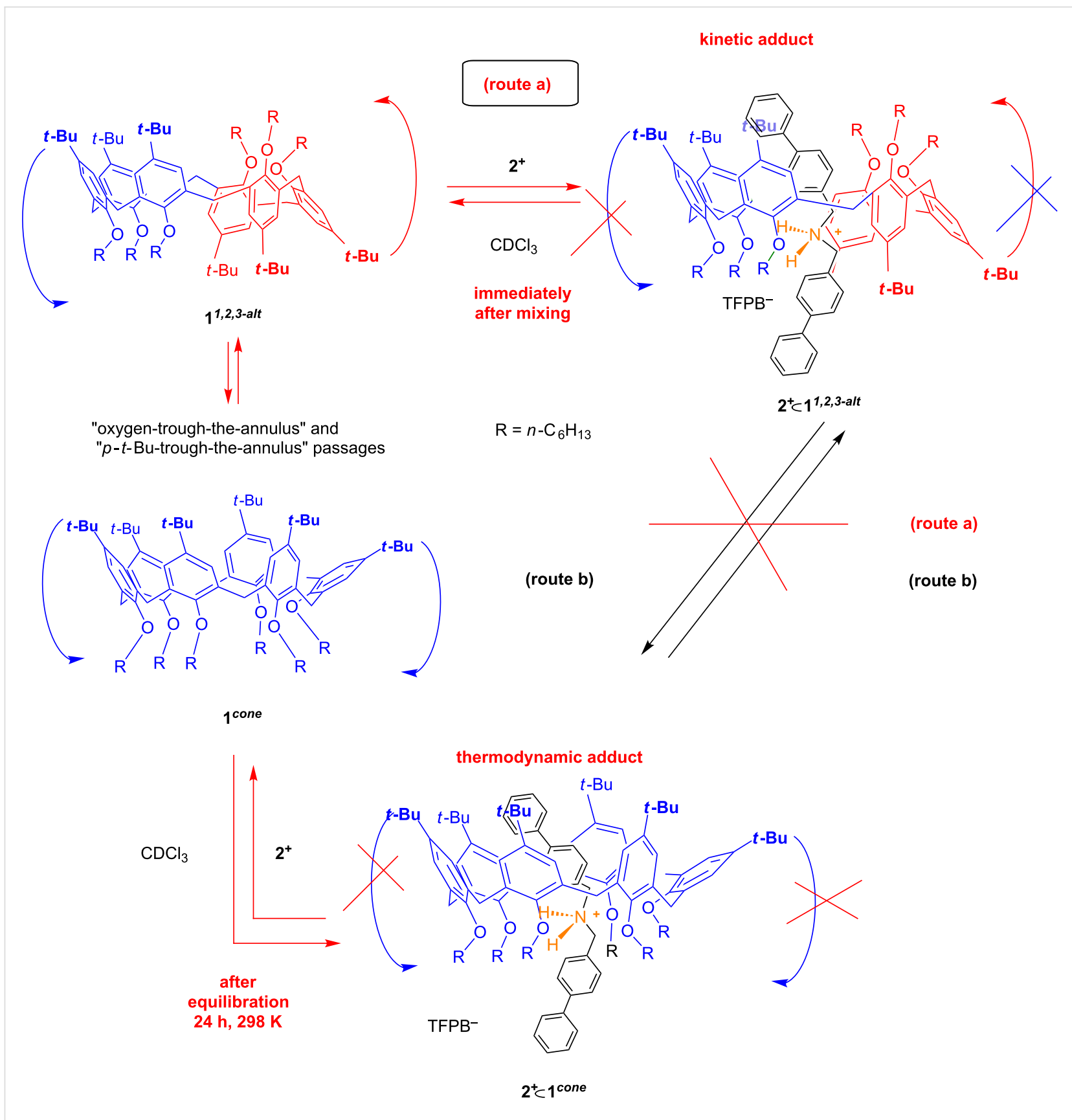

Figure 5: Possible mechanism for the formation of the two atropoisomeric pseudo[2]rotaxanes $2^{+} \subset 1^{\text {cone }}$ and $2^{+} \subset 1^{1,2,3-a l t}$.

$\mathbf{1}$ and $\mathbf{2}^{+}$, immediately after mixing in $\mathrm{CDCl}_{3}$, revealed the presence of a single AX systems at 3.53/4.73, which correlates with a carbon resonance at $28.9 \mathrm{ppm}$, respectively, due to the $\mathrm{ArCH}_{2} \mathrm{Ar}$ methylene groups between syn-oriented Ar rings. A close inspection of the 2D HSQC spectrum revealed the presence of a cross-peak at 3.93/36.5 ppm attributable to an $\mathrm{ArCH}_{2} \mathrm{Ar}$ methylene bridge between anti-oriented Ar rings. These data clearly indicate that calixarene-wheel $\mathbf{1}$ adopts the 1,2,3-alternate conformation in pseudorotaxane $2^{+} \subset 1^{1,2,3-a l t}$ (Figure 5 and Figure 6).
A further inspection of the 1D and 2D (COSY-45 and HSQC) spectra of the 1:1 mixture of $\mathbf{1}$ and $\mathbf{2}^{+}$in $\mathrm{CDCl}_{3}$ immediately after mixing, revealed the presence of a less abundant pseudo[2]rotaxane species in which probably the calixarene wheel 1 adopts a cone conformation $2^{+} \subset 1^{\text {cone }}$ (Figure 5). Initially, the ratio between the two isomeric pseudorotaxane $2^{+} \subset 1^{\text {cone }} / 2^{+} \subset 1^{1,2,3-a l t}$ is $1 / 20$, as calculated by integration of the corresponding ${ }^{1} \mathrm{H}$ NMR signals. Interestingly, after $10 \mathrm{~h}$ at $298 \mathrm{~K}$ (Figure 6), the intensity of the ${ }^{1} \mathrm{H}$ NMR signals of pseudorotaxane $2^{+} \subset 1^{1,2,3-a l t}$ was decreased while that of 
thermodynamic adduct

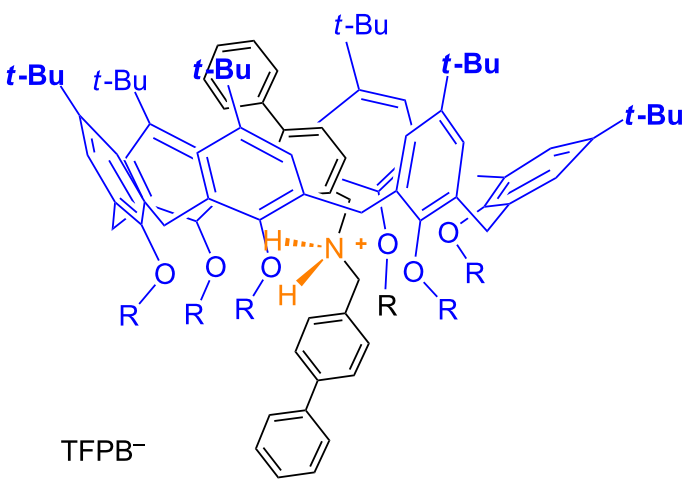

$2^{+} \subset 1^{\text {cone }}$

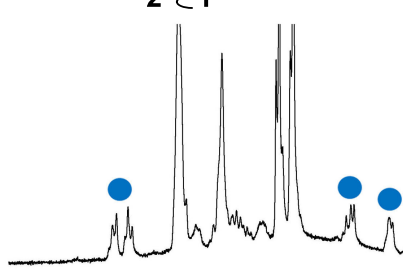

kinetic adduct

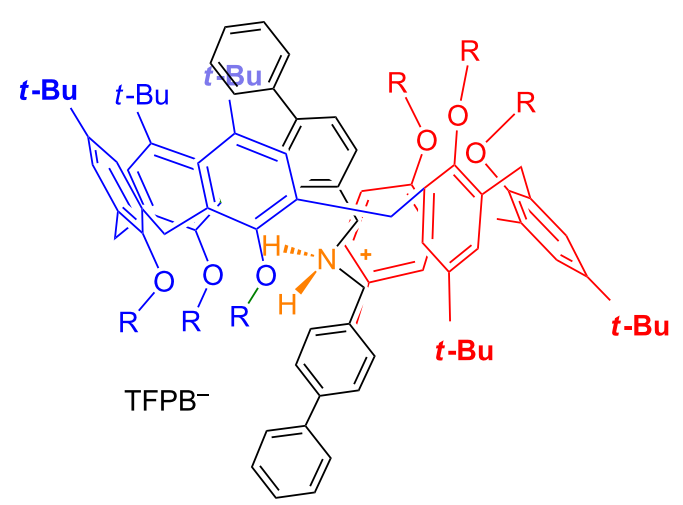

$2^{+} \subset 1^{1,2,3-a l t}$
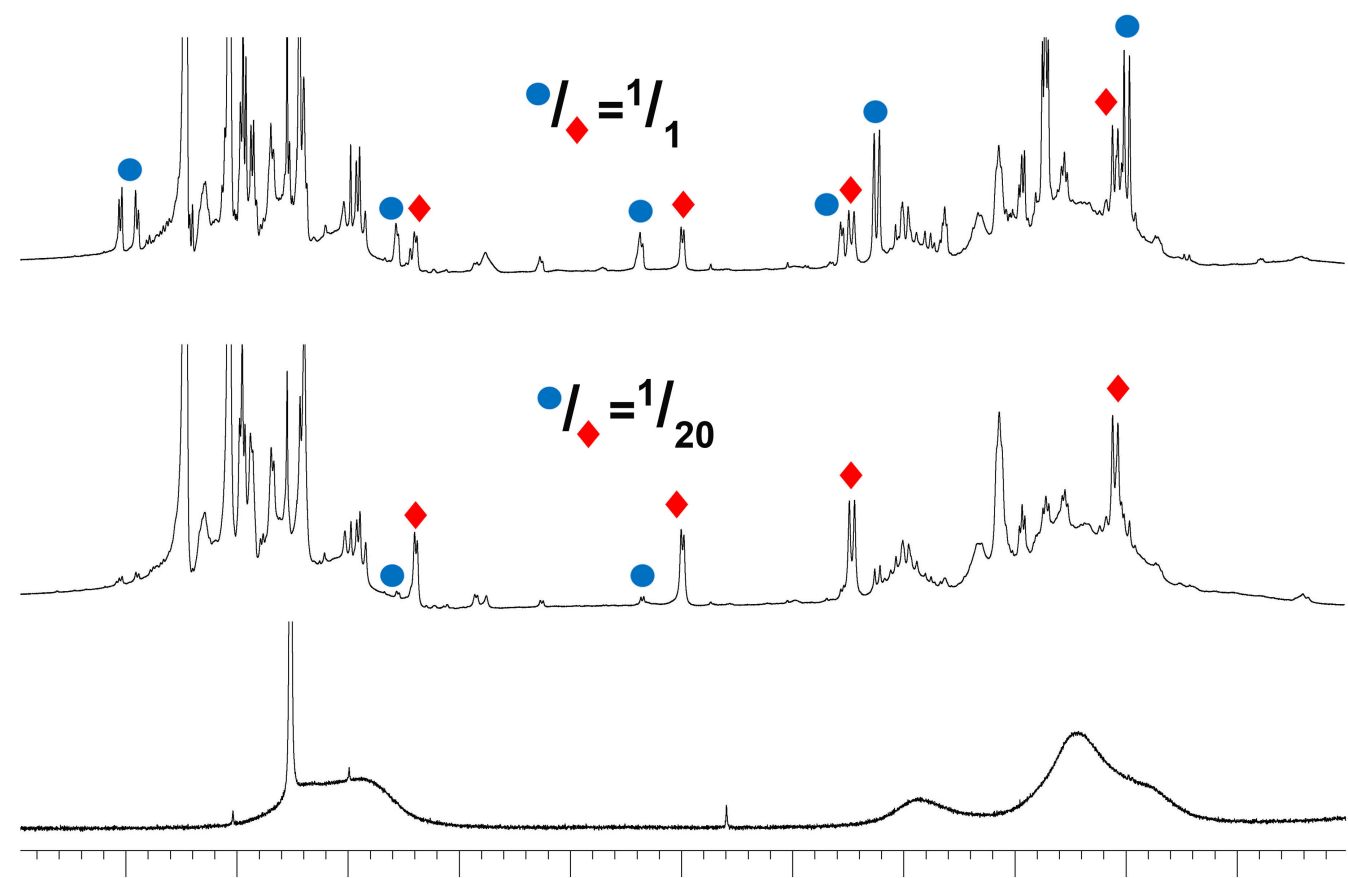

\section{$\begin{array}{lllllllllll}8.0 & 7.5 & 7.0 & 6.5 & 6.0 & 5.5 & 5.0 & 4.5 & 4.0 & 3.5 & \text { ppm }\end{array}$}

Figure 6: ${ }^{1} \mathrm{H}$ NMR spectra $\left(600 \mathrm{MHz}, \mathrm{CDCl}_{3}, 298 \mathrm{~K}\right)$ of, from bottom to top: hexahexyloxycalix[6]arene 1 ; a $1: 1$ mixture (0.003 M) of 1 and $\mathbf{2}^{+} \cdot \mathrm{TFPB}^{-}$ immediately after mixing; after $10 \mathrm{~h}$; after $18 \mathrm{~h}$.

$\mathbf{2}^{+} \subset \mathbf{1}^{\text {cone }}$ was increased. After $18 \mathrm{~h}$ at $298 \mathrm{~K}$, the disappearance of $2^{+} \subset 1^{1,2,3-a l t}$ was complete and only $2^{+} \subset 1^{\text {cone }}$ pseudorotaxane could be detected by $1 \mathrm{D}$ and 2D NMR studies (Figure 6). In fact, a 2D COSY spectrum of the 1:1 mixture of 1 and $2^{+}$in $\mathrm{CDCl}_{3}$, after $18 \mathrm{~h}$ at $298 \mathrm{~K}$, showed the presence of an
$\mathrm{ArCH}_{2} \mathrm{Ar} \mathrm{AX}$ system at 3.47/4.62 ppm which correlates in the HSQC spectrum with a carbon resonance at 28.4 ppm related to syn-oriented Ar rings. An AX system was present in the COSY spectrum at $4.78 / 5.68 \mathrm{ppm}$ attributable to aromatic protons of the axle $2^{+}$shielded inside the calixarene cavity. This 
shielded AX system correlates in the HSQC spectrum with aromatic carbon resonances at 129.8 and 126.8 ppm, respectively.

The ${ }^{1} \mathrm{H}$ NMR spectrum of the mixture of $\mathbf{1}$ and $\mathbf{2}^{+}$in $\mathrm{CDCl}_{3}$ remained unchanged after $48 \mathrm{~h}$ at $298 \mathrm{~K}$, thus showing that the system had reached the equilibrium condition. At this point, an apparent association constant of $6.2 \pm 0.3 \times 10^{3} \mathrm{M}^{-1}$ was calculated by quantitative ${ }^{1} \mathrm{H}$ NMR analysis (tetrachloroethane as internal standard) [37] for the formation of $2^{+} \subset 1^{\text {cone }}$ pseudorotaxane. In conclusion, after the initial formation of the kinetically favored pseudorotaxane $2^{+} \subset 1^{1,2,3-a l t}$ (Figure 5), the thermodynamic pseudorotaxane $\mathbf{2}^{+} \subset \mathbf{1}^{\text {cone }}$ prevails (Figure 5 and Figure 6). As demonstrated above, the 1,2,3-alternate conformation of $\mathbf{1}$ is the most populated in solution, consequently, the threading of this conformation, besides being faster, it is also favored by its abundance in solution.

The greater thermodynamic stability of the $2^{+} \subset 1^{\text {cone }}$ atropoisomer over the $2^{+} \subset \mathbf{1}^{1,2,3-a l t}$ one, was confirmed by DFT calculations at the B3LYP/6-31G(d,p) level of theory using Grimme's dispersion corrections $(\operatorname{IOp}(3 / 124=3))$ [42]. The DFT-optimized structure of the $\mathbf{2}^{+} \subset \mathbf{1}^{\text {cone }}$ atropoisomeric pseudorotaxane (Figure 7, left) results stabilized by two H-bond interactions between the ammonium group and the oxygen atoms of the calixarene wheel $\mathbf{1}$, (average $\mathrm{N} \cdots \mathrm{O}$ distance $=3.10 \AA$; average $\mathrm{N}-\mathrm{H} \cdots \mathrm{O}$ angle $=157^{\circ}$ ). In addition, $\mathrm{C}-\mathrm{H} \cdots \pi$ interactions were detected among the methylene groups of the axle $\mathbf{2}^{+}$inside the calix cavity, and the aromatic rings of $\mathbf{1}$ [42], ( average $\mathrm{C}-\mathrm{H} \cdots \pi^{\text {centroid }}$ distance $=3.17 \AA[42]$; average $\mathrm{C}-\mathrm{H} \cdots \pi^{\text {centroid }}$ angle $\left.=160^{\circ}[43]\right)$.

In addition, the biphenyl portion of $\mathbf{2}^{+}$hosted inside the calix cavity was involved in $\pi \cdots \pi$ interactions with the aromatic walls (Figures S11-S13, Supporting Information File 1) and $\mathrm{C}-\mathrm{H} \cdots \pi$ interactions with the tert-butyl groups of the calixarene wheel (Figure S13, Supporting Information File 1). Differently, in the DFT-optimized structure of $\mathbf{2}^{+} \subset \mathbf{1}^{1,2,3-a l t}$ atropoisomer (Figure 7, right), the stabilization of the $2^{+} \subset 1^{1,2,3-a l t}$ atropoisomer was brought, principally by two $\mathrm{H}$-bonding interactions between the ammonium group of $\mathbf{2}^{+}$and the oxygen atoms of anti-oriented phenol rings of $\mathbf{1}$ with an average $\mathrm{N} \cdots \mathrm{O}$ distance of $3.05 \AA$ and a narrower $\mathrm{N}-\mathrm{H} \cdots \mathrm{O}$ angle of $167.1^{\circ}$. Single-point calculations at the B3LYP/6-31G(d,p) level of theory using Grimme's dispersion corrections ( $\operatorname{IOp}(3 / 124=3))$, indicated that the $2^{+} \subset 1^{\text {cone }}$ atropoisomer was more stable than the $2^{+} \subset 1^{1,2,3-a l t}$ one by $2.4 \mathrm{kcal} \mathrm{mol}^{-1}$. At this point, it is worthy to consider the interconversion between the two isomeric pseudorotaxane $2^{+} \subset 1^{1,2,3-a l t}$ and $2^{+} \subset 1^{\text {cone }}$. It could take place through two possible mechanisms (Figure 5): a) de-threading of axle $\mathbf{2}^{+}$from
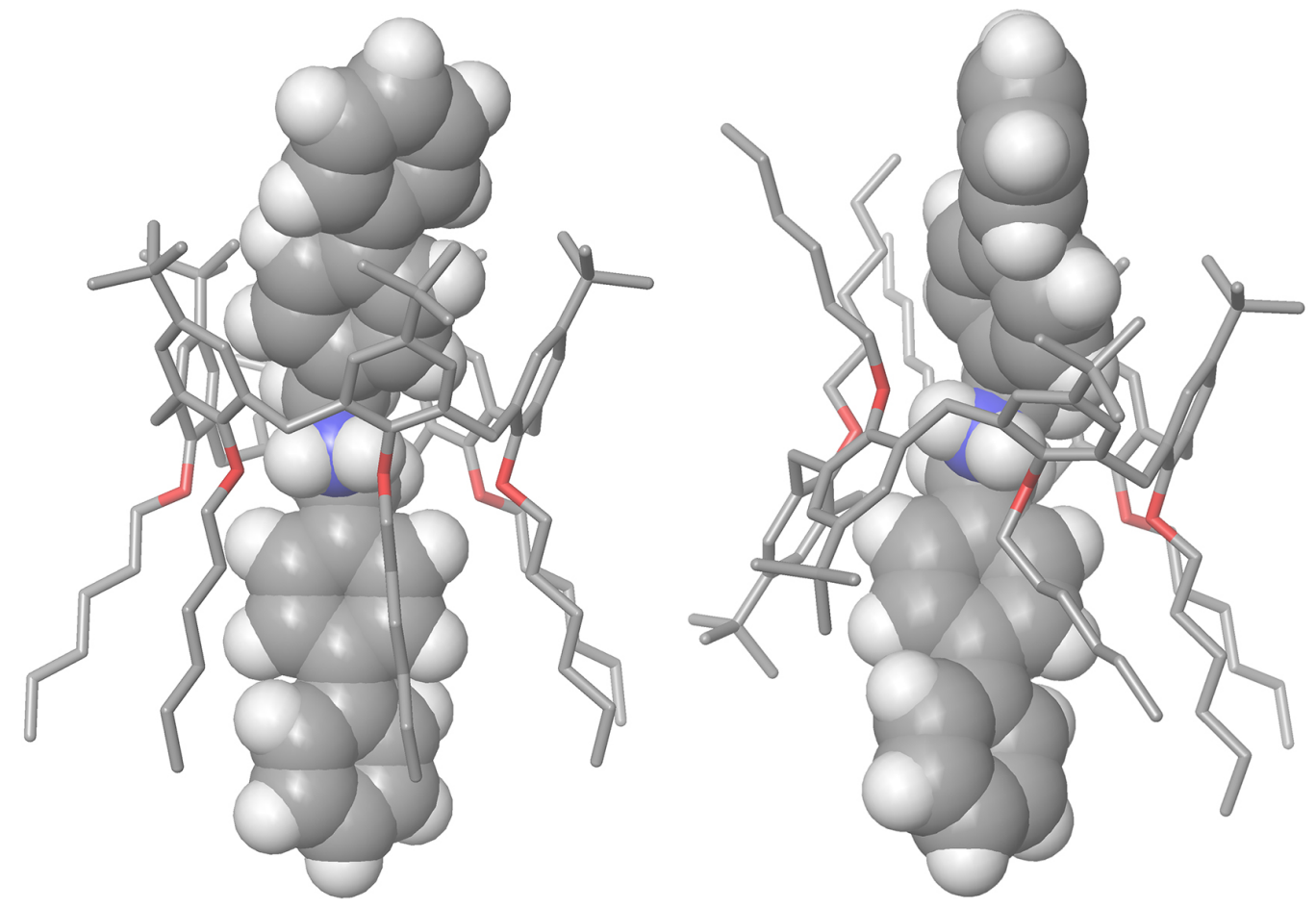

Figure 7: DFT-optimized structures of the: (left) $2^{+} \subset 1^{\text {cone }}$ and (right) $2^{+} \subset 1^{1,2,3-a l t}$ pseudorotaxane atropoisomers calculated at B3LYP/6-31G(d,p) level of theory and using Grimme's dispersion corrections $(I O p(3 / 124=3))$. 
$2^{+} \subset 1^{1,2,3-a l t}$ and a subsequent re-threading with 1 in a cone conformation; b) a direct conformational interconversion between the 1,2,3-alternate and cone conformations of the calixarene wheel $\mathbf{1}$ in both $\mathbf{2}^{+} \subset \mathbf{1}$ pseudorotaxanes. Previously reported data [34] clearly showed that the mechanism " $b$ " in Figure 5 can be ruled out because the presence of an axle inside the cavity of 1 impedes the "through-the-annulus" passage of both rims of $\mathbf{1}$ From this consideration, we concluded that the two pseudorotaxanes $2^{+} \subset 1^{1,2,3-a l t}$ and $2^{+} \subset 1^{\text {cone }}$ can be considered as two atropoisomeric forms. In fact, the interconversion between them cannot be obtained by simple rotation around chemical bonds of the calixarene wheel, which is blocked by the presence of the axle inside its cavity.

Previously [34] we reported a similar case in which the monostoppered alkylbenzylammonium axle $\mathbf{6}^{+}$gives rise to two atropoisomeric pseudorotaxanes $6^{+} \subset 1^{\text {cone }}$ and $6^{+} \subset 1^{1,2,3-a l t}$ (Figure 8). Also in this instance, the pseudorotaxanes $6^{+} \subset 1^{1,2,3-a l t}$ and $6^{+} \subset 1^{\text {cone }}$ were observed as the kinetic and thermodynamic adduct, respectively, with an interconversion time of $12 \mathrm{~h}$ at $353 \mathrm{~K}$. A further example regards the threading of the narrower penta- $O$-methyl-p-tert-butylcalix[5]arene 7 with pentylbenzylammonium axle $\mathbf{8}^{+}$[35]. Two atropoisomeric pseudorotaxanes were formed, namely $\mathbf{8}^{+} \subset 7^{\text {cone }}$ and $\mathbf{8}^{+} \subset 7^{\text {paco }}$ (Figure 9), in which the calix[5]-wheel adopted a cone and a partial-cone conformation, respectively [35]. Also in this case, the atropoisomer with an "inverted" calixarene wheel $\mathbf{8}^{+} \subset 7^{\text {paco }}$ is the kinetic product, while the other with a calix-cone conformation $\mathbf{8}^{+} \subset 7^{\text {cone }}$ is the thermodynamic one [35].

At this point we turned our attention to the threading properties of bis(4-trifluoromethylbenzyl)ammonium axle $\mathbf{3}^{+}$. When $\mathbf{1}$ and $3^{+}$. TFPB $^{-}$were mixed in $\mathrm{CDCl}_{3}$ two atropoisomeric pseudo[2]rotaxane, $\mathbf{3}^{+} \subset \mathbf{1}^{\text {cone }}$ and $\mathbf{3}^{+} \subset \mathbf{1}^{1,2,3-\text { alt }}$ (Figure 10), were formed in a 1/10 ratio, as revealed by $1 \mathrm{D}$ and 2D NMR studies. Also in this case, after equilibration at $298 \mathrm{~K}$ for $24 \mathrm{~h}$, this preference was reversed in favour of the $3+\subset \mathbf{1}^{\text {cone }}$ atropoisomer, with a $3^{+} \subset 1^{\text {cone }} / 3^{+} \subset 1^{1,2,3-a l t}$ ratio of $8 / 1$. From the equilibrium mixture, an apparent association constant of $9.3 \pm 0.4 \times 10^{2} \mathrm{M}^{-1}$ was calculated by quantitative ${ }^{1} \mathrm{H}$ NMR analysis (tetrachloroethane as internal standard) for the formation of $3^{+} \subset \mathbf{1}^{\text {cone }}$ pseudorotaxane. In a similar way, an apparent association constant of $120 \pm 15 \mathrm{M}^{-1}$ was found for $3^{+} \subset \mathbf{1}^{1,2,3-\text { alt }}$ pseudorotaxane.

As evidenced for axle $\mathbf{2}^{+}$, also in this case, after the initial formation of the kinetic pseudorotaxane $3^{+} \subset 1$ 1,2,3-alt (Figure 10), the thermodynamic atropoisomer $\mathbf{3}^{+} \subset \mathbf{1}^{\text {cone }}$ prevails. However, differently from the $\mathbf{2}^{+}$case where the kinetic product was no longer detectable in the final equilibrium mixture, here a size-

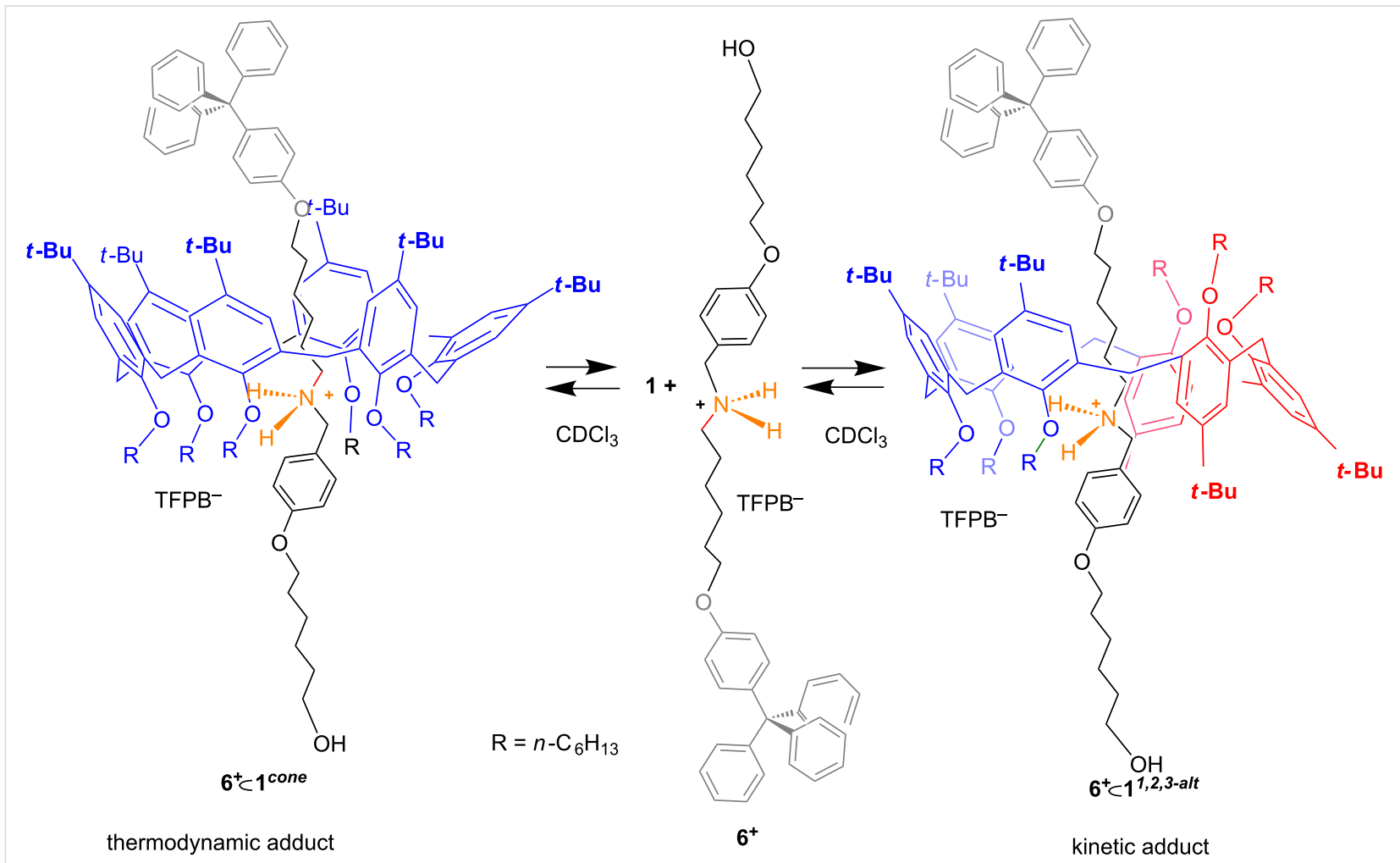

Figure 8: The two pseudorotaxane atropoisomers obtained by threading hexahexyloxycalix[6]arene 1 with monostoppered alkylbenzylammonium axle $6^{+}$. 


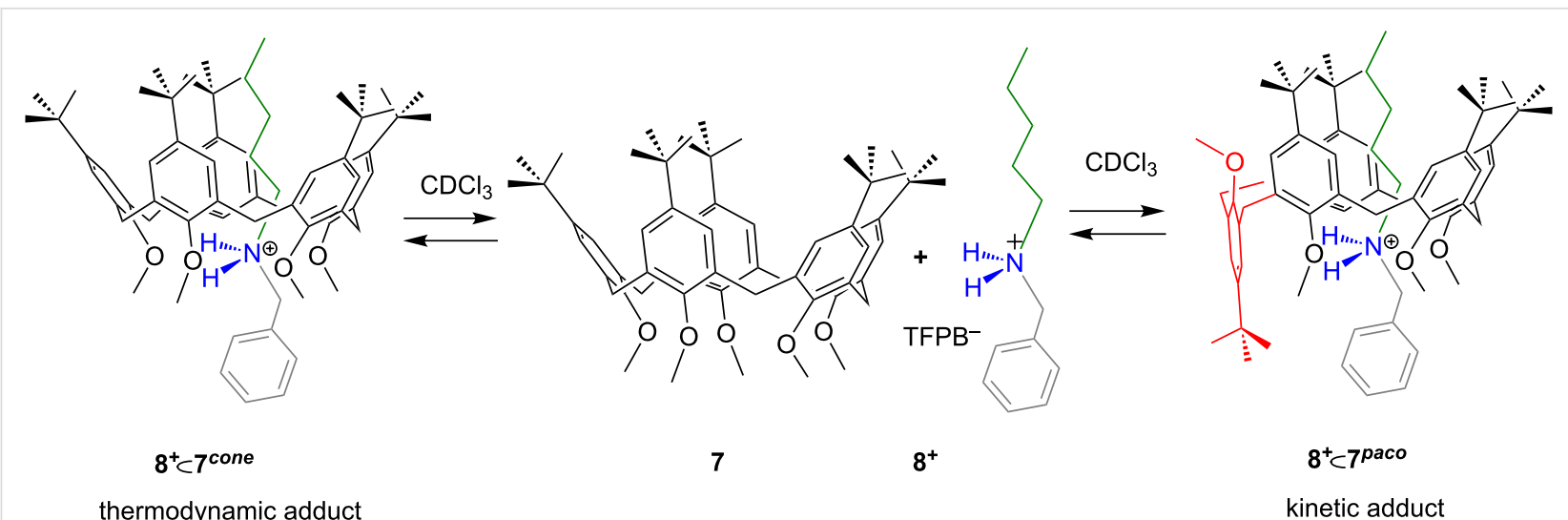

Figure 9: The two pseudorotaxane atropoisomers obtained by threading penta-O-methyl-p-tert-butylcalix[5]arene 7 with pentylbenzylammonium axle $\mathbf{8}^{+}$.

able amount of the kinetic pseudorotaxane $3^{+} \subset 1^{1,2,3-a l t}$ can be observed at the equilibrium indicating a smaller energy difference with respect to the thermodynamic atropoisomer $3^{+} \subset 1^{\text {cone }}$. This can be ascribed to a higher destabilization of the cone atropoisomer due to a higher number of unfavourable "fluorophobic" interactions between the $\mathrm{CF}_{3}$ group and the $t$-Bu-Ar moieties.

\section{Conclusion}

We have here reported a study on isomeric pseudorotaxanes in which the isomerism arises by the different conformation adopted by the calix[6] arene wheel. Among the eight possible discrete conformations of the calix[6]arene macrocycle, the cone and 1,2,3-alternate ones were observed in the pseudorotaxane architectures obtained by threading a hexahexyloxycalix[6]arene with axles bearing biphenyl or trifluoromethylbenzyl moieties. The interconversion between the cone and 1,2,3-alternate conformations occurs, in free calix[6]arene, by means of the "oxygen-through-the-annulus" and/or " $p$-substituent-through-the-annulus" passages. The presence of the ammonium axles inside the calixarene cavity prevents these passages; consequently two atropoisomeric pseudorotaxanes were formed. We showed that the interconversion between the two atropoisomeric pseudorotaxanes can only occur through a mechanism of de-threading/re-threading of the axle. In all the examined cases, the 1,2,3-alternate and cone atropoisomers are the kinetic and thermodynamic pseudorotaxane, respectively. We do believe that novel and intriguing calixarene-based mechanomolecules, with expanded properties or functions, could be obtained by an appropriate stoppering or catenation of such atropoisomeric pseudorotaxanes.

\section{Experimental}

ESI(+)-MS measurements were performed on a Micromass Bio-Q triple quadrupole mass spectrometer equipped with elec- trospray ion source, using a mixture of $\mathrm{H}_{2} \mathrm{O} / \mathrm{CH}_{3} \mathrm{CN}(1: 1)$ and $5 \% \mathrm{HCOOH}$ as solvent. Flash chromatography was performed on Merck silica gel $(60,40-63 \mu \mathrm{m})$. All chemicals were reagent grade and were used without further purification. Anhydrous solvents were purchased from Aldrich. When necessary compounds were dried in vacuo over $\mathrm{CaCl}_{2}$. Reaction temperatures were measured externally. Reactions were monitored by TLC on Merck silica gel plates $(0.25 \mathrm{~mm})$ and visualized by UV light, or by spraying with $\mathrm{H}_{2} \mathrm{SO}_{4}-\mathrm{Ce}\left(\mathrm{SO}_{4}\right)_{2}$ or phosphomolybdic acid. NMR spectra were recorded on a Bruker Avance-600 spectrometer $\left[600\left({ }^{1} \mathrm{H}\right)\right.$ and $\left.150 \mathrm{MHz}\left({ }^{13} \mathrm{C}\right)\right]$, Bruker Avance-400 spectrometer $\left[400\left({ }^{1} \mathrm{H}\right)\right.$ and $100 \mathrm{MHz}$ $\left.\left({ }^{13} \mathrm{C}\right)\right]$, Bruker Avance-300 spectrometer $\left[300\left({ }^{1} \mathrm{H}\right)\right.$ and $75 \mathrm{MHz}$ $\left.\left({ }^{13} \mathrm{C}\right)\right]$, or Bruker Avance-250 spectrometer [250 $\left({ }^{1} \mathrm{H}\right)$ and $63 \mathrm{MHz}\left({ }^{13} \mathrm{C}\right)$ ]; chemical shifts are reported relative to the residual solvent peak $\left(\mathrm{CHCl}_{3}: \delta 7.26, \mathrm{CDCl}_{3}: \delta 77.23 ; \mathrm{CD}_{3} \mathrm{OH}\right.$ : $\delta 4.87, \mathrm{CD}_{3} \mathrm{OD}: \delta 49.0$;). Standard pulse programs, provided by the manufacturer, were used for 2D COSY-45, 2D ROESY and 2D NOESY/EXSY experiments.

\section{General procedure for the preparation of $\mathbf{2}^{+}$ and $\mathbf{3}^{+}$. TFPB $^{-}$salts}

Derivative 4 (or 5, $2.2 \mathrm{mmol}$ ) was dissolved at $60{ }^{\circ} \mathrm{C}$ in liquid $\left(\mathrm{Me}_{3} \mathrm{Si}\right)_{2} \mathrm{NH}(0.71 \mathrm{~g}, 4.4 \mathrm{mmol}, 0.92 \mathrm{~mL}), \mathrm{LiClO}_{4}(0.02 \mathrm{~g}$, $2.2 \mathrm{mmol}$ ) was added and the reaction was kept under stirring at $60{ }^{\circ} \mathrm{C}$ until a white solid was formed (30 min). The solution was allowed to cool down at room temperature and dry $\mathrm{MeOH}$ $(4.0 \mathrm{~mL})$ was added. The mixture was kept under stirring for $2 \mathrm{~h}$ and then cooled at $0{ }^{\circ} \mathrm{C}$. $\mathrm{NaBH}_{4}(1.12 \mathrm{~g}, 11.0 \mathrm{mmol})$ was added and the mixture was kept under stirring at $0{ }^{\circ} \mathrm{C}$ for $15 \mathrm{~min}$ and then allowed to warm up at room temperature. After 2 hours the solvent was removed, the solid was dissolved in ethyl acetate $(100 \mathrm{~mL})$ and washed with an aqueous saturated solution of $\mathrm{NaHCO}_{3}(100 \mathrm{~mL})$ and $\mathrm{H}_{2} \mathrm{O}(50 \mathrm{~mL})$. The organic layer was dried over $\mathrm{Na}_{2} \mathrm{SO}_{4}$ and the solvent was removed under reduced 


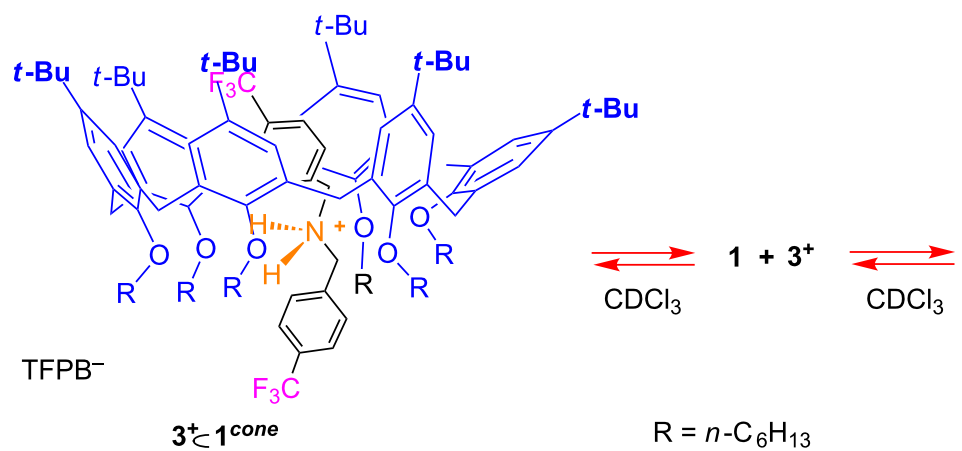

thermodynamic adduct
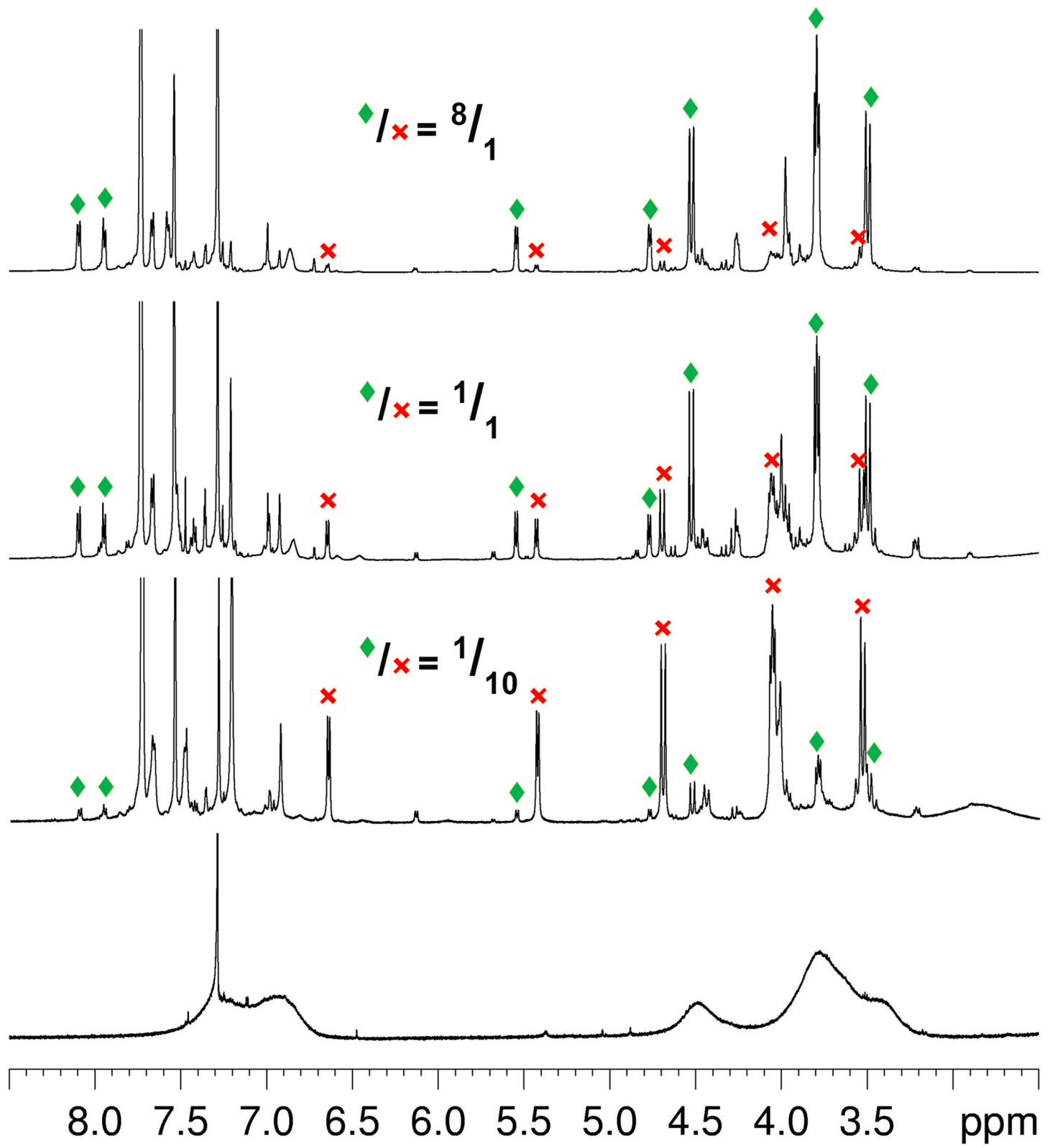

Figure 10: ${ }^{1} \mathrm{H}$ NMR spectra $\left(600 \mathrm{MHz}, \mathrm{CDCl}_{3}, 298 \mathrm{~K}\right.$ ) of, from bottom to top: hexahexyloxycalix[6]arene 1; a $1: 1 \mathrm{mixture}(0.003 \mathrm{M})$ of 1 and $3^{+}$.TFPB immediately after mixing; after $2 \mathrm{~h}$; after $18 \mathrm{~h}$, mechanism for the formation of the two atropoisomeric pseudo[2]rotaxanes $3^{+} \subset 1^{\text {cone }}$ and $3^{+} \subset 1^{1,2,3-a l t}$ 
pressure, to give secondary amine derivative. Amine was used without further purification in the next step. Secondary amine derivative $(1.16 \mathrm{mmol})$ was dissolved in $\mathrm{MeOH}(20 \mathrm{~mL})$ at room temperature and an aqueous solution of $\mathrm{HCl}(37 \% \mathrm{w} / \mathrm{w}$, $0.20 \mathrm{~mL}$ ) was added dropwise. The mixture was kept under stirring for $30 \mathrm{~min}$, until the formation of a white precipitate. The solid was collected by filtration, washed with $\mathrm{MeOH}(10 \mathrm{~mL})$ and $\mathrm{CH}_{3} \mathrm{CN}(10 \mathrm{~mL})$ and dried under vacuum to give the ammonium chloride derivative. The chloride salt $(0.68 \mathrm{mmol})$ and sodium tetrakis[3,5-bis(trifluoromethyl)phenyl]borate $(0.60 \mathrm{~g}$, $0.68 \mathrm{mmol})$ were dissolved in dry $\mathrm{MeOH}(15 \mathrm{~mL})$. The solution was stirred for $18 \mathrm{~h}$ in the dark, then the solvent was removed and deionized water was added, obtaining a light brown precipitate, that was filtered off and dried under vacuum to give threads $\mathbf{2}^{+}$or $\mathbf{3}^{+}$.

\section{Derivative $\mathbf{2}^{+}$}

Light brown solid, $0.73 \mathrm{~g}, 0.60 \mathrm{mmol}, 88 \%$ yield (respect chloride salt); $\mathrm{mp} 135-138{ }^{\circ} \mathrm{C}$; $\operatorname{ESI}(+) \mathrm{MS}(\mathrm{m} / \mathrm{z}): 350.2\left(\mathrm{M}^{+}\right)$; ${ }^{1} \mathrm{H}$ NMR (400 MHz, $\left.\mathrm{CD}_{3} \mathrm{OD}, 298 \mathrm{~K}\right) \delta 4.34$ (s, 4H), 7.37-7.41 (overlapped, 6H), 7.61-7.67 (overlapped, 20H), 7.76 (d, $J=7.8 \mathrm{~Hz}, 4 \mathrm{H}) ;{ }^{13} \mathrm{C} \mathrm{NMR}\left(100 \mathrm{MHz}, \mathrm{CD}_{3} \mathrm{OD}, 298 \mathrm{~K}\right) \delta 51.7$, $118.4,118.4,118.5,121.7,124.4,127.1,128.0,128.8,129.0$, $130.0,130.1,130.2,130.3(2), 130.5(2), 130.6,131.2,131.5$, 135.8, 141.3, 143.9, 162.1, 162.6, 163.1, 163.6; anal. calcd for $\mathrm{C}_{58} \mathrm{H}_{36} \mathrm{BF}_{24} \mathrm{~N}$ : C, 57.40; H, 2.99; found: C, 57.39; H, 3.01.

\section{Derivative $\mathbf{3}^{+}$}

Light brown solid, $0.57 \mathrm{~g}, 0.48 \mathrm{mmol}, 70 \%$ yield (respect chloride salt); $\mathrm{mp} 125-128{ }^{\circ} \mathrm{C}$; $\operatorname{ESI}(+) \mathrm{MS}(\mathrm{m} / \mathrm{z}): 334.1\left(\mathrm{M}^{+}\right)$; ${ }^{1} \mathrm{H}$ NMR (300 MHz, CD $\left.3 \mathrm{OD}, 298 \mathrm{~K}\right) \delta 3.7$ (s, 4H), 7.30-7.32 (overlapped, $20 \mathrm{H}$ ); ${ }^{13} \mathrm{C} \mathrm{NMR}\left(75 \mathrm{MHz}, \mathrm{CD}_{3} \mathrm{OD}, 298 \mathrm{~K}\right) \delta 52.6$, $118.3,118.5,118.6,122.0,125.4,127.3,128.3,128.9,129.1$, 130.0, 130.3, 130.4, 130.5(2), 130.6, 131.2, 131.6, 135.8, 141.4, 144.0, 162.2, 162.7, 163.2, 163.5; anal. calcd for $\mathrm{C}_{48} \mathrm{H}_{26} \mathrm{BF}_{30} \mathrm{~N}$ : C, 48.14; H, 2.19; found: C, 48.13; H, 2.17 .

\section{General procedure for the preparation of pseudorotaxane derivatives}

The calixarene derivative $\mathbf{1}(3.0 \mathrm{mM})$ and ammonium salt $\mathbf{2}^{+}$or $\mathbf{3}^{+}(3.0 \mathrm{mM})$ were dissolved in $\mathrm{CDCl}_{3}(0.5 \mathrm{~mL})$. Each solution was sonicated for $15 \mathrm{~min}$ at room temperature and then was transferred into a NMR tube for 1D and 2D NMR spectra acquisition.

Determination of apparent $\boldsymbol{K}_{\text {ass }}$ value for pseudorotaxanes $2^{+} \subset 1^{\text {cone }}, 3^{+} \subset 1^{\text {cone }}$ and $3^{+} \subset 1^{1,2,3-a l t}$, by quantitative ${ }^{1} \mathrm{H}$ NMR analysis. The sample was prepared by dissolving calixarene 1 $\left(3.0 \times 10^{-3} \mathrm{M}\right)$ and the ammonium TFPB salt $\mathbf{2}^{+}$or $\mathbf{3}^{+}$ $\left(3.0 \times 10^{-3} \mathrm{M}\right)$ in $\mathrm{CDCl}_{3}(0.5 \mathrm{~mL})$ containing $1.0 \mu \mathrm{L}$ of TCHE $(d=1.596 \mathrm{~g} / \mathrm{mL})$ as an internal standard. The complex concen- tration [complex] was evaluated by integration of the ${ }^{1} \mathrm{H}$ NMR signal of TCHE versus the signals of the pseudorotaxane. The following equation was used to obtain the moles of the complex:

$$
\frac{G_{\mathrm{a}}}{G_{\mathrm{b}}}=\frac{F_{\mathrm{a}}}{F_{\mathrm{b}}} \times \frac{N_{\mathrm{b}}}{N_{\mathrm{a}}} \times \frac{M_{\mathrm{a}}}{M_{\mathrm{b}}},
$$

where $G_{\mathrm{a}}=$ grams of TCHE, $G_{\mathrm{b}}=$ grams of pseudorotaxane, $F_{\mathrm{a}}$ and $F_{\mathrm{b}}=$ areas of the signal of the TCHE and shielded aromatic protons of axle inside the calixarene cavity, $N_{\mathrm{a}}$ and $N_{\mathrm{b}}=$ numbers of nuclei that cause the signals $\left(N_{\mathrm{a}}\right.$ for TCHE; $N_{\mathrm{b}}$ for pseudorotaxane) and $M_{\mathrm{a}}$ and $M_{\mathrm{b}}=$ molecular masses of TCHE (a) and pseudorotaxane (b).

\section{Supporting Information}

\section{Supporting Information File 1}

VT NMR studies of hexyloxycalix[6]arene 1, 2D COSY and HSQC spectra of atropoisomeric pseudorotaxanes, details of DFT calculations and atomic coordinates. [https://www.beilstein-journals.org/bjoc/content/ supplementary/1860-5397-14-186-S1.pdf]

\section{Acknowledgements}

The authors acknowledge the Regione Campania (POR CAMPANIA FESR 2007/2013 O.O.2.1, CUP B46D14002660009) for the FT-ICR mass spectrometer facilities, FarmaBioNet (CUP B25C13000230007), the Centro di Tecnologie Integrate per la Salute" (CITIS, project PONa3_00138) for the $600 \mathrm{MHz}$ NMR facilities and Università di Salerno for financial support.

\section{ORCID ${ }^{\circledR} \mathrm{iDs}$}

Carmine Gaeta - https://orcid.org/0000-0002-2160-8977 Carmen Talotta - https://orcid.org/0000-0002-2142-6305 Placido Neri - https://orcid.org/0000-0003-4319-1727

\section{References}

1. Bruns, C. J.; Stoddart, J. F. The Nature of the Mechanical Bond: From Molecules to Machines, 1st ed.; John Wiley \& Sons, 2017.

2. Feringa, B. L. Angew. Chem., Int. Ed. 2017, 56, 11060-11078. doi:10.1002/anie.201702979

3. Sauvage, J.-P. Angew. Chem., Int. Ed. 2017, 56, 11080-11093. doi:10.1002/anie.201702992

4. Stoddart, J. F. Angew. Chem., Int. Ed. 2017, 56, 11094-11125. doi:10.1002/anie.201703216

5. Kassem, S.; Lee, A. T. L.; Leigh, D. A.; Marcos, V.; Palmer, L. I.; Pisano, S. Nature 2017, 549, 374-378. doi:10.1038/nature23677

6. Zhao, D.; Neubauer, T. M.; Feringa, B. L. Nat. Commun. 2015, 6, No. 6652. doi:10.1038/ncomms7652 
7. Barat, R.; Legigan, T.; Tranoy-Opalinski, I.; Renoux, B.; Péraudeau, E.; Clarhaut, J.; Poinot, P.; Fernandes, A. E.; Aucagne, V.; Leigh, D. A.; Papot, S. Chem. Sci. 2015, 6, 2608-2613. doi:10.1039/C5SC00648A

8. Van der Berg, J. P.; Velema, W. A.; Szymanski, W.; Driessen, A. J. M.; Feringa, B. L. Chem. Sci. 2015, 6, 3593-3598. doi:10.1039/C5SC00215J

9. Lewis, J. E. M.; Galli, M.; Goldup, S. M. Chem. Commun. 2017, 53, 298-312. doi:10.1039/C6CC07377H

10. Yu, H.; Luo, Y.; Beverly, K.; Stoddart, J. F.; Tseng, H.; Heath, J. R. Angew. Chem., Int. Ed. 2003, 42, 5706-5711. doi:10.1002/anie.200352352

11. Green, J. E.; Choi, J. W.; Boukai, A.; Bunimovich, Y.; Johnston-Halperin, E.; Delonno, E.; Luo, Y.; Sheriff, B. A.; Xu, K.; Shin, Y. S.; Tseng, H.-R.; Stoddart, J. F.; Heath, J. R. Nature 2007, 445, 414-417. doi:10.1038/nature05462

12. Li, Z.-Y.; Zhang, Y.; Zhang, C.-W.; Chen, L.-J.; Wang, C.; Tan, H.; Yu, Y.; Li, X.; Yang, H.-B. J. Am. Chem. Soc. 2014, 136, 8577-8589. doi:10.1021/ja413047r

13. Wang, W.; Chen, L.-J.; Wang, X.-Q.; Sun, B.; Li, X.; Zhang, Y.; Shi, J.; Yu, Y.; Zhang, L.; Liu, M.; Yang, H.-B. Proc. Natl. Acad. Sci. U. S. A. 2015, 112, 5597-5601. doi:10.1073/pnas.1500489112

14. Shivanyuk, A.; Rebek, J. J. Am. Chem. Soc. 2002, 124, 12074-12075. doi:10.1021/ja020607a

15. Bordoli, R. J.; Goldup, S. M. J. Am. Chem. Soc. 2014, 136, 4817-4820. doi:10.1021/ja412715m

16. Neal, E. A.; Goldup, S. M. Chem. Commun. 2014, 50, 5128-5142. doi:10.1039/C3CC47842D

17. Talotta, C.; De Simone, N. A.; Gaeta, C.; Neri, P. Org. Lett. 2015, 17, 1006-1009. doi:10.1021/acs.orglett.5b00115

18. Fuller, A.-M. L.; Leigh, D. A.; Lusby, P. J. J. Am. Chem. Soc. 2010, 132, 4954-4959. doi:10.1021/ja1006838

19. Talotta, C.; Gaeta, C.; Pierro, T.; Neri, P. Org. Lett. 2011, 13 2098-2101. doi:10.1021/ol2005159

20. Talotta, C.; Gaeta, C.; Neri, P. Org. Lett. 2012, 14, 3104-3107. doi:10.1021/ol3011997

21. Talotta, C.; Gaeta, C.; Qi, Z.; Schalley, C. A.; Neri, P. Angew. Chem., Int. Ed. 2013, 52, 7437-7441. doi:10.1002/anie.201301570

22. Neri, P.; Sessler, J. L.; Wang, M.-X., Eds. Calixarenes and Beyond; Springer: Dordrecht, 2016. doi:10.1007/978-3-319-31867-7

23. Tommasone, S.; Talotta, C.; Gaeta, C.; Margarucci, L.; Monti, M. C.; Csapullo, A.; Macchi, B.; Prete, S. P.; De Araujo, A. L.; Neri, P. Angew. Chem., Int. Ed. 2015, 54, 15405-15409. doi:10.1002/anie.201508651

24. Soriente, A.; De Rosa, M.; Fruilo, M.; Lepore, L.; Gaeta, C.; Neri, P. Adv. Synth. Catal. 2005, 347, 816-824. doi:10.1002/adsc.200505023

25. Gaeta, C.; Gregoli, L.; Martino, M.; Neri, P. Tetrahedron Lett. 2002, 43 , 8875-8878. doi:10.1016/S0040-4039(02)02204-9

26. Ikeda, A.; Shinkai, S. Chem. Rev. 1997, 97, 1713-1734. doi:10.1021/cr960385x

27. Bifulco, G.; Gomez-Paloma, L.; Riccio, R.; Gaeta, C.; Troisi, F.; Neri, P. Org. Lett. 2005, 7, 5757-5760. doi:10.1021/ol052166g

28. Bifulco, G.; Riccio, R.; Gaeta, C.; Neri, P. Chem. - Eur. J. 2007, 13, 7185-7194. doi:10.1002/chem.200700238

29. Kanamathareddy, S.; Gutsche, C. D. J. Org. Chem. 1992, 57, 3160-3166. doi:10.1021/jo00037a037

30. Jaime, C.; De Mendoza, J.; Prados, P.; Nieto, P. M.; Sanchez, C. J. Org. Chem. 1991, 56, 3372-3376. doi:10.1021/jo00010a036

31. Magrans, J. O.; de Mendoza, J.; Pons, M.; Prados, P. J. Org. Chem. 1997, 62, 4518-4520. doi:10.1021/jo961943a
32. Arduini, A.; Orlandini, G.; Secchi, A.; Credi, A.; Silvi, S.; Venturi, M. Calixarene Threading by Viologen-Based Axles. In Calixarenes and Beyond; Neri, P.; Sessler, J. L.; Wang, M.-X., Eds.; Springer: Dordrecht, 2016; pp 761-781. doi:10.1007/978-3-319-31867-7_29

33. Gaeta, C.; Talotta, C.; De Rosa, M.; Soriente, A.; Neri, P. Calixarene Threading via Superweak Anion. In Calixarenes and Beyond; Neri, P.; Sessler, J. L.; Wang, M.-X., Eds.; Springer: Dordrecht, 2016; pp 783-809. doi:10.1007/978-3-319-31867-7_30

34. La Manna, P.; Talotta, C.; Gaeta, C.; Soriente, A.; De Rosa, M.; Neri, P. J. Org. Chem. 2017, 82, 8973-8983. doi:10.1021/acs.joc.7b01388

35. De Rosa, M.; Talotta, C.; Gaeta, C.; Soriente, A.; Neri, P.; Pappalardo, S.; Gattuso, G.; Notti, A.; Parisi, M. F.; Pisagatti, I. J. Org. Chem. 2017, 82, 5162-5168. doi:10.1021/acs.joc.7b00406

36. Gaeta, C.; Talotta, C.; Margarucci, L.; Casapullo, A.; Neri, P. J. Org. Chem. 2013, 78, 7627-7638. doi:10.1021/j0401206j

37. Gaeta, C.; Talotta, C.; Mirra, S.; Margarucci, L.; Casapullo, A.; Neri, P. Org. Lett. 2013, 15, 116-119. doi:10.1021/ol303142c

38. Gaeta, C.; Talotta, C.; Farina, F.; Teixeira, F. A.; Marcos, P. A.; Ascenso, J. R.; Neri, P. J. Org. Chem. 2012, 77, 10285-10293. doi:10.1021/jo3019945

39. Arduini, A.; Bussolati, R.; Credi, A.; Secchi, A.; Silvi, S.; Semeraro, M.; Venturi, M. J. Am. Chem. Soc. 2013, 135, 9924-9930. doi:10.1021/ja404270c

40. Gaeta, C.; Troisi, F.; Neri, P. Org. Lett. 2010, 12, 2092-2095. doi:10.1021/ol100578z

41. van Duynhoven, J. P. M.; Janssen, R. G.; Verboom, W.; Franken, S. M.; Casnati, A.; Pochini, A.; Ungaro, R.; de Mendoza, J.; Nieto, P. M.; Prados, P.; Reinhoudt, D. N. J. Am. Chem. Soc. 1994, 116, 5814-5822. doi:10.1021/ja00092a036

42. Grimme, S. J. Comput. Chem. 2006, 27, 1787-1799. doi:10.1002/jcc.20495

43. Suezawa, H.; Ishihara, S.; Umezawa, Y.; Tsuboyama, S.; Nishio, M. Eur. J. Org. Chem. 2004, 4816-4822. doi:10.1002/ejoc.200400373

\section{License and Terms}

This is an Open Access article under the terms of the Creative Commons Attribution License (http://creativecommons.org/licenses/by/4.0). Please note that the reuse, redistribution and reproduction in particular requires that the authors and source are credited.

The license is subject to the Beilstein Journal of Organic Chemistry terms and conditions: (https://www.beilstein-journals.org/bjoc)

The definitive version of this article is the electronic one which can be found at: $\underline{\text { doi: } 10.3762 / \text { bjoc. } 14.186}$ 